10. Huber, A. H., Nelson, J. \& Wies, W. I. Three-dimensional structure of the Armadillo repeat of $\beta$ catenin. Cell 90, 871-882 (1997)

11. Kawashima, T., Berthet-Colominas, C., Wulff, M., Cusack, S. \& Leberman, R. The structure of the Escherichia coli EF-Tu.EF-Ts complex at $2.5 \AA$ resolution. Nature 379, 511-518 (1996).

12. Wang, Y., Jiang, Y., Meyering-Voss, M., Sprintzl, M. \& Sigler, P. Crystal structure of the EF-Tu.EF-Ts complex from Thermus thermophilus. Nature Struct. Biol. 4, 650-656 (1997).

13. Yu, H. \& Schreiber, S. L. Structure of guanine-nucleotide-exchange factor human Mss4 and identification of its Rab-interacting surface. Nature 376, 788-791 (1995).

14. Harrison, C. J., Hayer-Hartl, M., Di Liberto, M., Hartl, F. U. \& Kuriyan, J. Crystal structure of the nucleotide exchange factor GrpE bound to the ATPase domain of the molecular chaperone DnaK. Science 276, 431-435 (1997)

15. Renault, L. et al. The $1.7 \AA$ crystal structure of the regulator of chromosome condensation (RCC1) reveals a seven-bladed propeller. Nature 392, 97-101 (1998).

16. Scheffzek, K. et al. The ras-rasGAP complex: structural basis for GTPase activation and its loss in oncogenic mutants. Science 277, 333-338 (1997).

17. Rittinger, K., Walker, P. A., Eccleston, J. F., Smerdon, S. J. \& Gamblin, S. J. Structure at 1.65 A of RhoA and its GTPasep-activating protein in complex with a transition-state analog. Nature 389, 758-762 (1997).

18. Paris, S. et al. Role of protein-phospholipid interactions in the activation of ARF1 by the guanine nucleotide exchange factor Arno. J. Biol. Chem. 272, 22221-22226 (1997).

19. Jacquet, E., Baouz, S. \& Parmeggiani, A. Characterization of a mammalian C-CDC25Mm exchange factor and kinetic properties of the exchange reaction intermediate p21.C-CDC25Mm. Biochemistry 34, 12347-12354 (1995).

20. Verroti, A. C. et al. RAS residues that are distant form the GDP binding site play a critical role in dissociation factor-stimulated release of GDP. EMBO J. 11, 2855-2862 (1992).

21. Segal, M., Willumsen, B. \& Levitzk, A. Residues crucial for Ras interaction with GDP-GTP exchangers. Proc. Natl Acad. Sci. USA 90, 5564-5568 (1993).

22. Antonny, B., Béraud-Dufour, S., Chardin, P. \& Chabre, M. N-terminal hydrophobic residues of the G- protein ADP-ribosylation factor-1 insert into membrane phospholipids upon GDP to GTP exchange. Biochemistry 36, 4675-4684 (1997).

23. Schimmöller, F., Itin, C. \& Pfeffer, S. Vesicle traffic: get your coat! Curr. Biol. 7, R235-R237 (1997).

24. Amor, J. C., Harrison, D. H., Kahn, R. A. \& Ringe, D. Structure of the human ADP-ribosylation factor 1 complexed with GDP. Nature 372, 704-708 (1994)

25. Madej, T., Gibrat, J. F. \& Bryant, S. H. Threading a database of protein cores. Proteins Struct. Funct. Genet. 23, 356-369 (1995).

26. Schalk, I. et al. Structure and mutational analysis of Rab GDP-dissociation inhibitor. Nature 381, 42 48 (1996).

27. Keep, N. H. et al. A modulator of rho family G proteins, rhoGDI, binds these G proteins via an immunoglobulin-like domain and a flexible N-terminal arm. Structure 5, 623-633 (1997).

28. Kolanus, W. et al. $\alpha$ L $\beta 2$ integrin/LFA-1 binding to ICAM-1 induced by cytohesin-1, a cytoplasmic regulatory molecule. Cell 86, 233-242 (1996).

29. Collaborative Computational Project No. 4. The CCP4 suite: programs for protein crystallography. Acta Crystallogr. D 50, 760-763 (1994).

30. De la Fortelle, E. \& Bricogne, G. Maximum-likeliwood heavy-atom parameter refinement for multiple isomorphous replacement and multiwavelength anomalous diffraction methods. Methods Enzymol. 276, 472-494 (1997)

Acknowledgements. We thank the staff at the LURE for making outstation W32 available to us; M. Roth at the ESRF for beamlight assistance at outstation D2AM; S. Bryant and T. Madej for the Protein Data Bank survey with VAST; J.-F. Gibrat for sequence-threading calculations; S. Paris for unpublished observations; and M. Chabre and J. Janin for discussions. This work was supported by the Association pour la Recherche contre le Cancer and by Zénéca Pharma (France). M.M. was supported by an EMBO fellowship.

Correspondence and requests for materials should be addressed to J.C. (e-mail: cherfils@lebs.cnrs-gif fr). Coordinates have been deposited in the Brookhaven Data Bank under accession code 1PBV.

\title{
erratum
}

\section{Radical alterations in the roles of homeobox genes during echinoderm evolution}

\section{Christopher J. Lowe \& Gregory A. Wray}

Nature 389, 718-721 (1997)

The labelling of Fig. 1 of this Letter was incomplete in several places. The corrected figure is reproduced below.

a
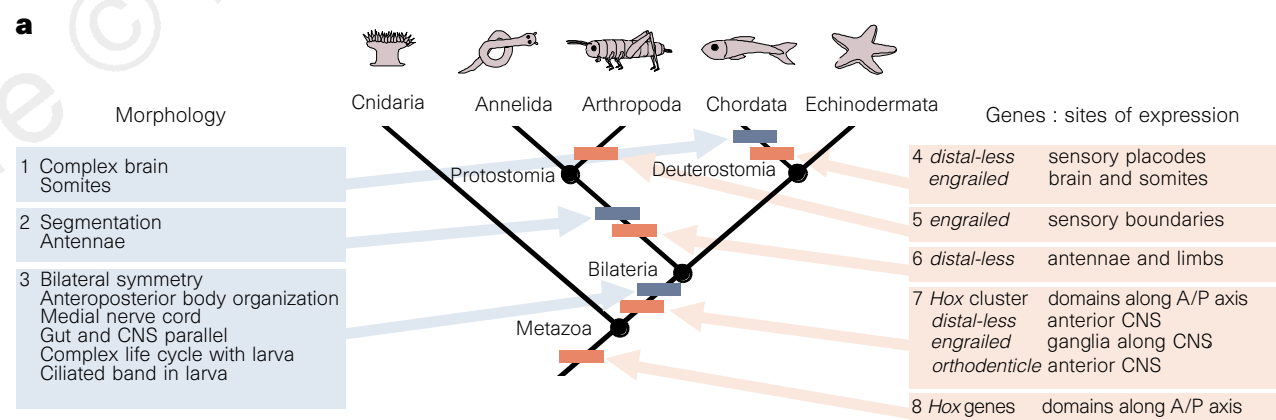

b

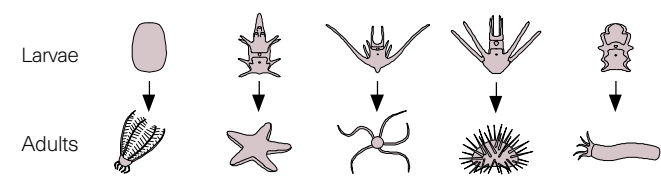

feather stars sea stars brittle stars sea urchins sea cucumbers

Morphology (Crinoidea) (Asteroidea) (Ophiuroidea) (Echinoidea) (Holothuroidea)

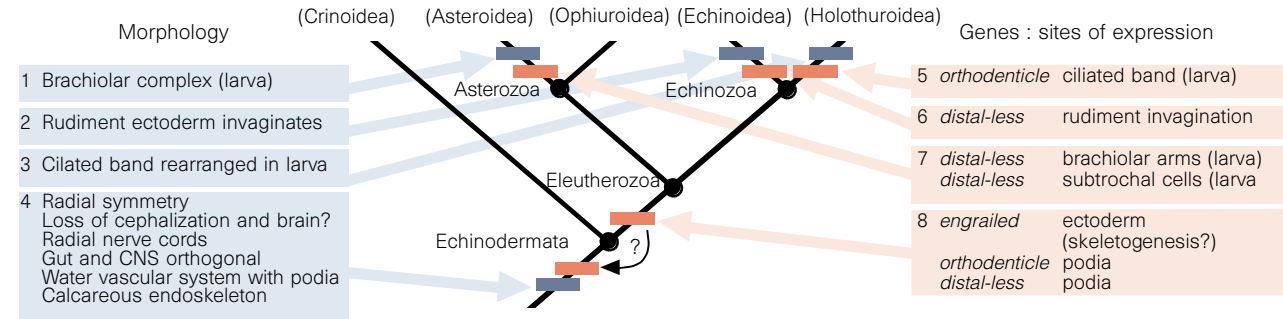


15. Fiedler, P. C. \& Bernard, H. J. Tuna aggregation and feeding near fronts observed in satellite imagery. Continent. Shelf Res. 7, 871-881 (1987).

16. Richards, L. J. \& Schnute, J. T. An experimental and statistical approach to the question: is CPUE an index of abundance? Can. J. Fish. Aquat. Sci. 43, 1214-1227 (1986).

17. Chen, W. Y. Assessment of Southern Oscillation sea level pressure indices. Month. Weath. Rev. 110 800-807 (1982).

18. Cane, M. A., Zebiak, S. E. \& Dolan, S. C. Experimental forecasts of El Niño. Nature 321, 827-832 (1986).

19. Barnett, T. P. et al. On the prediction of the El Niño of 1986-87. Science 241, 192-196 (1988).

20. Chen, D., Zebiak, S., Busalacchi, A. J. \& Cane, M. A. An improved procedure for El Niño forecasting: implications for predictability. Science 269, 1699-1702 (1995).

21. Chavez, F. P. \& Barber, R. T. An estimate of new production in the equatorial Pacific. Deep Sea Res. 34, $1229-1243$ (1987)

22. Sharp, G. D. \& Dizon, A. E. (ed.) The Physiological Ecology of Tunas (Academic, San Diego, 1978).

23. Dragovitch, A. The food of skipjack and yellowfin tunas in the Atlantic ocean. Fish. Bull. US 70, 10871110 (1970).

24. Roger, C. \& Grandperrin, R. Pelagic food webs in the tropical Pacific. Limnol. Oceanogr. 21, 731-735 (1976)

25. Roger, C. The plankton of the tropical western Indian ocean as a biomass indirectly supporting surface tunas (yellowfin, Thunnus albacares and skipjack, Katsuwonus pelamis). Environ. Biol. Fish. 39, $161-$ 172 (1994).

26. Vinogradov, M. E. in Analysis of Marine Ecosystems (ed. Longhurst, A. R.) (Academic, San Diego, 1981)

27. Hansen, D. V. \& Swenson, M. S. Mixed layer circulation during EqPac and some thermochemical implications for the equatorial cold tongue. Deep Sea Res. 43, 707-724 (1996).

28. Piontkovski, S. A. \& Williams, R. Multiscale variability of tropical ocean zooplankton biomass. ICES J. Mar. Sci. 52, 643-656 (1995).

29. Eckman, J. E. Modelling physical-biological coupling in the ocean: the U.S. GLOBEC Program. Deep Sea Res. 41, 1-5 (1994).

30. Hampton, J. Estimates of tag-reporting and tag-shedding rates in a large-scale tuna tagging experiments in the western tropical Pacific Ocean. Fish. Bull. US 95, 68-79 (1997).

Acknowledgements. We thank colleagues who provided data used in this study, particularly J. Joseph, R. Allen and M. Hinton for providing catch data for eastern Pacific tuna fisheries, and R. Grandperrin, J.-M. Andre and K. Bigelow for comments. This work was supported by the European Union-funded South Pacific Regional Tuna Resource Assessment and Monitoring Project of the Oceanic Fisherie Programme of the South Pacific Commission.

Radical alterations in the roles of homeobox genes during echinoderm evolution

\section{Christopher J. Lowe \& Gregory A. Wray}

Department of Ecology and Evolution, State University of New York, Stony Brook, New York 11794, USA

Echinoderms possess one of the most highly derived body architectures of all metazoan phyla, with radial symmetry, a calcitic endoskeleton, and a water vascular system ${ }^{1,2}$. How these dramatic morphological changes evolved has been the subject of extensive speculation and debate ${ }^{3-5}$, but remains unresolved. Because echinoderms are closely related to chordates and postdate the protostome/deuterostome divergence ${ }^{2,3,6,7}$, they must have evolved from bilaterally symmetrical ancestors ${ }^{1-6}$. Here we report the expression domains in echinoderms of three important developmental regulatory genes (distal-less, engrailed and orthodenticle), all of which encode transcription factors that contain a homeodomain ${ }^{8}$. Our findings show that the reorganization of body architecture involved extensive changes in the deployment and roles of homeobox genes. These changes include modifications in the symmetry of expression domains and the evolution of several new developmental roles, as well as the loss of roles conserved between arthropods and chordates. Some of these modifications seem to have evolved very early in the history of echinoderms, whereas others probably evolved during the subsequent diversification of adult and larval morphology. These results demonstrate the evolutionary lability of regulatory genes that are widely viewed as conservative.

Orthologues of the developmental regulatory genes distal-less, engrailed and orthodenticle are present in arthropods and chordates, where there are similarities in their roles and expression domains: distal-less in proximodistal patterning during limb outgrowth ${ }^{9}$; engrailed in neurogenesis along the axis of the central nervous system $^{10}$; and orthodenticle in the specification of anterior structures $^{11}$ (Fig. 1a). Each gene also has other functions during development ${ }^{8-11}$, however, and it is not even clear whether these superficially similar roles are conserved between phyla or evolved independently ${ }^{12,13}$. We examined the expression of these genes in several echinoderm species representing four of the five extant classes and a diversity of adult and larval morphologies within the phylum.

The three homeoproteins are expressed in fivefold radially symmetrical patterns during development of the radial adult body (Fig. 2) in all echinoderms examined (Figs 3d,e, 4c-e, 5). Based on time of expression, none of these genes seems to be involved in establishing radial symmetry, but all three act downstream of the genes that are. Most radial expression domains correspond to structures that are unique to echinoderms, such as podia, endoskeleton, spines, arm-tip ectoderm, and imaginal rudiment. Podia (tube-feet) function in locomotion, feeding and sensory perception $^{1,2}$, and are extensions of the water vascular system, an organ system unique to echinoderms ${ }^{1,2,6}$. The gene orthodenticle is expressed in the podia of brittle stars (Fig. 4d) and sea urchins, and in the homologous ${ }^{14}$ buccal tentacles of sea cucumbers (sea stars were not examined). The gene distal-less is expressed in the podia of sea urchins ${ }^{9}$ (Fig. 3d) and sea stars, and in the buccal tentacles of sea cucumbers (Fig. 3e), but was not detected in the podia of brittle stars. In sea urchins, podial expression of distal-less begins within the imaginal rudiment at the distal end of the five primary podia soon after they form, and persists through early juvenile development. The calcitic endoskeleton of echinoderms evolved after their divergence from other deuterostome phyla ${ }^{2,4-6}$. Ectodermal expression of engrailed in brittle stars (Fig. 5a-e) is restricted to the nuclei of cells that overlie boundaries between newly forming skeletal ossicles. This spatial correlation is present beginning with the synthesis of the first ossicles of the adult skeleton (Fig. 5a, b) and persists as far into postmetamorphic juvenile development as we examined (Fig. 5c-e). This association suggests that engrailed is involved in patterning axial skeletogenesis, which is consistent with experimental evidence that skeletogenic mesenchyme cells in seaurchin larvae rely in part on ectodermally derived cues for patterning ${ }^{15}$. The spines of sea urchins are specialized derivatives of the endoskeleton ${ }^{2,14}$. Ectodermal expression of distal-less is evident at the tips of spines ${ }^{9}$, but was not detected in association with other skeletal elements in sea urchins or in other echinoderms examined. In brittle stars, orthodenticle is expressed in the ectoderm overlying the terminal ossicles at the tips of the arms, with diminishing expression proximally (Fig. 4e). Ectodermal expression was not detected overlying the homologous ${ }^{14}$ ocular ossicles in sea urchins. In sea urchins, a large imaginal rudiment gives rise to much of the postmetamorphic juvenile ${ }^{14,16}$. In most sea urchins, an ectodermal invagination encloses the rudiment ${ }^{16}$. Initially, distalless is expressed in all these ectodermal cells, but is later restricted to the distal (inner) end of the invagination (Fig. 3a-c). No distal-less expression was detected in the rudiment ectoderm of echinoderms from other classes.

Each of these cases probably represents recruitment (co-option) of a homeobox gene to a new developmental role ${ }^{17,18}$, as the structures where expression occurs evolved after the divergence of echinoderms and chordates ${ }^{2,4-6}$. Role recruitment implies that the downstream targets of these genes in echinoderms include loci that are different from those in other phyla. Both engrailed and orthodenticle exist as single-copy genes in sea urchins ${ }^{19,20}$, and presumably other echinoderms, implying that these recruitment events occurred without gene duplication. (The copy number of distal-less has not been determined in any echinoderm.) In contrast, recruitment of developmental roles in chordates is often associated 
with gene duplication followed by divergence of developmental roles $^{17,21}$. Some features of expression are probably homologous among echinoderm classes (such as orthodenticle expression in podia), implying an origin over $450 \mathrm{Myr}$ ago $^{22}$, whereas others have a more restricted phylogenetic distribution (such as distalless in sea-urchin rudiments) and apparently evolved later (Fig. 1b).
Not all expression domains in echinoderms imply recruited developmental roles. In the brittle star Amphipholis squamata (Fig. 5f), engrailed is expressed in a subset of neuronal cell bodies (C. Lowe and M. Thorndyke, unpublished data) in paired ganglia along the five radial nerves. This expression is superficially similar to that in bilateral animals, in which engrailed is expressed within a
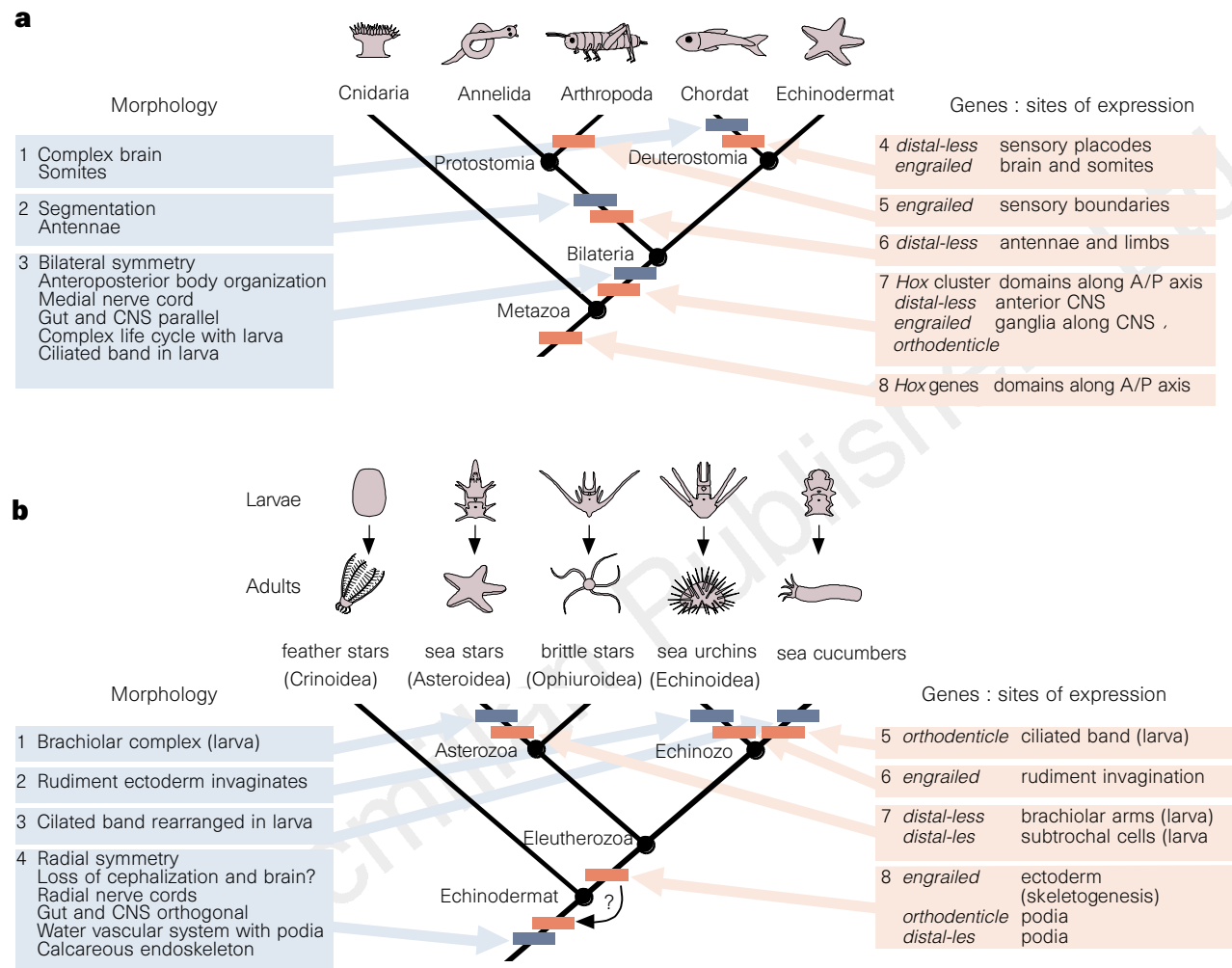

Figure 1 Evolutionary history of body architecture and regulatory genes within the Metazoa (a) and Echinodermata (b). Reconstructed changes in morphology (left) and in the developmental roles and expression domains of regulatory genes (right) are shown. The expression domains and roles of several regulatory genes are similar in arthropods and chordates $(\mathbf{a}, 8)^{8-11}$, despite their phylogenetic disjunction and morphological disparity ${ }^{2,5,6}$. These similarities probably reflect homology in basic architectural features, such as bilateral symmetry and an anteroposterior axis $(\mathbf{a}, 3)$ between protostomes and deuterostomes. Morphological features that distinguish phyla (such as $\mathbf{a}, 1$ ) and groups of related phyla( $\mathbf{a}, 2$ ) evolved later. In some such cases, changes in the developmental roles of regulatory genes (a, 5 and 7 ) have been identified that may have been involved in the origin of these derived structures ${ }^{9,10,17}$. The origin of echinoderms followed the divergence of arthropods and chordates, and involved substantive modifica- tions in basic body architecture $(\mathbf{b}, 2)^{1-6}$; already present was a complex life cycle involving a larva that fed using a ciliated band $(\mathbf{a}, 3)^{1-6}$. Data reported here and taken from the literature ${ }^{8-11,19}$ allow us to reconstruct changes in the expression domains of three regulatory genes during the origin and radiation of echinoderms. Several derived features of gene expression are shared by asterozoan and echinozoan echinoderm species (b, 7), implying that they were present before the divergence of these clades over $490 \mathrm{Myr} \mathrm{ago}^{22}$. The origin of these features could be even earlier (arrow near base of cladogram), but expression data are currently unavailable for crinoids, the most basal clade of extant echinoderms. Other features of gene expression appear to be limited to a single class (such as b, 4 and 6), suggesting later origins or subsequent losses within other lineages. Phylogenetic relationships are from refs 2, 6, 7 and 14.

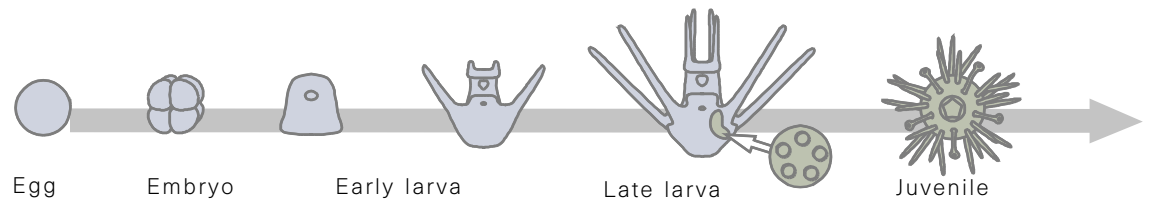

bilaterally symmetrical

left-right asymmetrical

radially symmetrical

Figure 2 Summary of echinoderm development. Echinoderm embryos and larvae are bilaterally symmetrical ${ }^{1,6,16}$. In late larvae, discrete populations of ectodermal and mesodermal cells on the left side of the body proliferate to form the imaginal adult rudiment (green crescent). The first radially symmetrical structures appear within the rudiment (disc near late larva). During metamorphosis, many larval tissues (blue) are lost, and the rudiment gives rise to much of the juvenile (green). Domains of regulatory gene expression fall into three distinct symmetry classes: bilateral in embryos and early larvae; left-right asymmetric in late larvae, during establishment of the imaginal rudiment; and radial during and after metamorphosis. 
serially repeated subset of ganglionic neurons along the anteroposterior axis ${ }^{10,23}$. It is possible that a neurogenic role for engrailed is widely conserved among triploblastic animals. However, the radial nerves of echinoderms are ancestrally organized in a zigzag along the proximodistal axis of the arms, and only in sea stars and brittle stars are the ganglia arranged in bilateral pairs ${ }^{14}$. Thus the superficial similarity of engrailed expression between brittle stars and bilateral animals is probably convergent. Another possibility for a conserved role in echinoderms is that of orthodenticle in the ectoderm of seaurchin embryos ${ }^{19}$.

Echinoderms begin development as bilaterally symmetrical embryos and larvae $e^{1,16}$. A few bilaterally symmetrical gene expression domains are present in larvae, notably the ciliated band of a sea-cucumber larvae, the brachiolar arms of starfish larvae, and the mesenchyme cells of sea-star larvae. Ciliated bands are present in larvae from all five extant classes, ${ }^{6,16}$, and are used for locomotion and feeding ${ }^{6}$. The gene orthodenticle is expressed in ectodermal cells of the circumferential ciliated bands of a bilateral sea-cucumber larva (Fig. 4f), but was not detected in the ciliated bands of any other echinoderm larvae. This restricted phylogenetic distribution suggests role recruitment after the evolutionary origin of the ciliated band (Fig. 1b), as the ciliated band almost certainly pre-dates the origin of echinoderms $\mathrm{s}^{2,6}$ (Fig. 1a). A similar case is the role of evenskipped in insect segmentation, which evolved after segmental body organization $^{10}$. Brachiolar arms are used for attachment to the benthos during settlement and metamorphosis ${ }^{1,16}$, and are present only in the larvae of sea stars ${ }^{16}$. Scattered cells within the ectoderm of
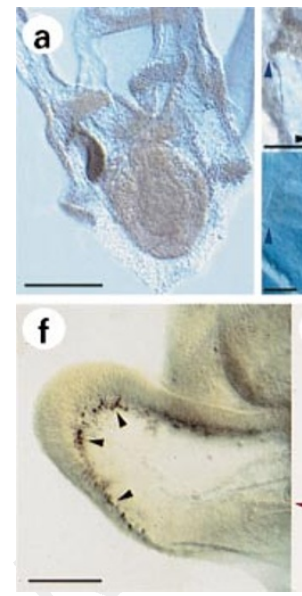
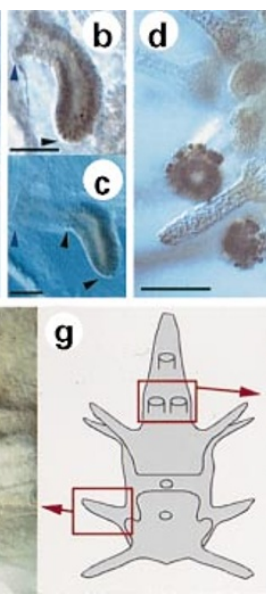
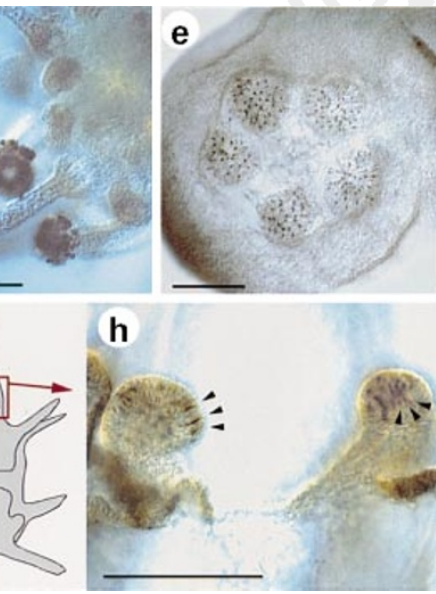

Figure 3 Expression of Distal-less protein. a, Mid-larva of the sea urchin Strongylocentrotus droebachiensis. Expression is present throughout the invagination that becomes the ectodermal component of the imaginal rudiment, which gives rise to the bulk of the adult body. This expression domain is present only on the left side of the larva. $\mathbf{b}$. Close-up $\mathbf{a}$, showing nuclear expression in all invaginating cells. In $\mathbf{b}$ and $\mathbf{c}$, blue arrowheads mark the opening of the invagination, and black arrowheads mark the extent of distal-less expression. c. Close-up of imaginal rudiment from later larva, showing expression restricted to cells at the distal (innermost) end of the invagination. d, Juvenile sea urchin, $S$. droebachiensis. Expression is limited to the distal ends of podia and spines. e, Rudiment in mid-larva of the sea cucumber Cucumaria miniata. Scattered nuclei in the ectoderm express Distal-less protein in the five primary podia; these are probably neurons. $\mathbf{f}$, Single arm from larva of a sea star (Evasterias troschelii) showing expression in mesodermal cells (probably subtrochal cells) lying just under the ectoderm near the arm tip (arrowheads). Expression of distal-less was not detected in other mesodermal cell types in asteroid larvae. $\mathbf{g}$. Generalized late starfish larva showing the location of structures shown in $\mathbf{f}$ and $\mathbf{h}$. $\mathbf{h}$, Two brachiolar arms from the larva of $E$. troschelii. The brachiolar complex is used for attachment to the benthos during settlement?. Scattered nuclei throughout the ectoderm of the distal pad in each brachiolar arm express Distal-less (arrowheads); these cells appear to be neurons. Scale bars: $\mathbf{a}, \mathbf{d}-\mathbf{g}, \mathbf{i}, 100 \mu \mathrm{m} ; \mathbf{b}, \mathbf{c}, 30 \mu \mathrm{m}$. the brachiolar arms express distal-less (Fig. 3h), and, judging by their shape, number and position, they are probably neurons or neuronal precursors. Expression of distal-less was also detected in mesenchyme cells (Fig. 3f) lining the tips of the larval arms in sea stars. On the basis of their location, these appear to be subtrochal cells, which link muscles to the body wall in sea star larvae $e^{24}$.

Each of these cases probably represents a role recruitment that occurred well after the origin of echinoderms, given that each is restricted to a single class. To our knowledge, these cases are the first reported examples of role recruitment associated with the evolution of exclusively larval structures. Many phyla differ from arthropods and chordates in patterning their larval and adult bodies at different times during development, and in containing larvae that are morphologically quite distinct from adults $\mathrm{s}^{2,5,6,16}$. Thus we predict that role recruitment associated with the origin and modification of larval structures will prove common in other metazoan phyla with complex life cycles, such as annelids, molluscs, nemerteans, platyhelminths and phoronids.

The paucity of conserved expression domains, and by implication developmental roles, for the three genes we examined contrasts with most comparisons between arthropods and chordates, which have emphasized evolutionary conservation ${ }^{8,11,25,26}$. It seems reasonable that conservation in expression domains is tied to morphological conservation, and that altered expression domains may have produced many large-scale evolutionary changes in morphology $y^{5,10,17}$. Accordingly, we predict that analyses of metazoan taxa with divergent adult body architectures (such as cnidarians, ctenophores,
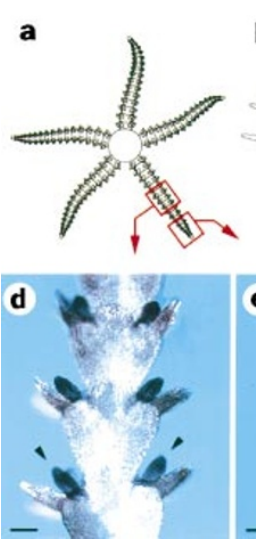
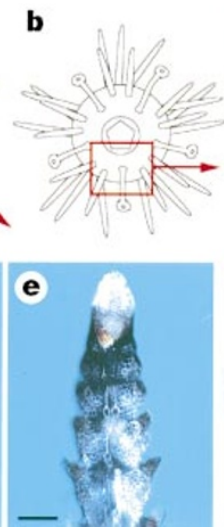
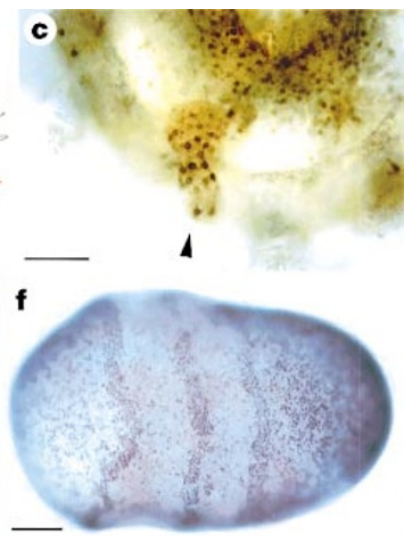

Figure 4 Expression of Orthodenticle protein. a, Generalized juvenile brittle star (oral view), showing location of structures shown in $\mathbf{d}$ and $\mathbf{e}$. b. Generalized juvenile sea urchin (oral view), showing location of structures shown in c. c, Close-up of single podium (arrowhead) from the sea urchin Strongylocentrotus droebachiensis. Distal-less expression is restricted to nuclei along the length of the podium and surrounding the mouth. $\mathbf{d}$, Oral surface of part of an arm from a juvenile brittle star (Amphipholis squamata). Ectodermal expression is evident throughout podia (arrowheads), which in brittle stars lack suckers. e, Tip of one arm from $A$. squamata. Expression is present at high levels throughout the ectoderm near the distal end of the arm, and declines proximally. $\mathbf{f}$, Mid-larva of the sea cucumber Psolus chitinoides. Expression is evident in three circumferential stripes (4-6 cells wide) within the ectoderm. These cells bear large cilia and make up the ciliated band, the locomotory organ in echinoderm larvae. Most ectodermal cells between the circumferential bands lack cilia at this stage, but a few have not yet lost them; these cells probably correspond to the nuclei expressing distal-less protein that are scattered throughout the ectoderm. Scale bars: c, f, $100 \mu \mathrm{m} ; \mathbf{d}, \mathbf{e}, 500 \mu \mathrm{m}$. 
brachiopods, bryozoans, rotifers and pterobranch hemichordates), will reveal many additional evolutionary changes in the developmental roles of homeobox genes that are widely considered conservative.

The highly derived body architecture of echinoderms evolved at least in part through extensive modifications in the roles and expression domains of regulatory genes inherited from their bilateral ancestors. Even the limited number of genes and species we examined demonstrates a remarkable evolutionary flexibility in genes that have previously been considered interesting mainly for their conserved roles in arthropods and chordates ${ }^{6,11,25,26}$. However, comparisons between these phyla must be supplemented with data from additional phyla if we are to understand the role played by regulatory genes in producing morphological change $\mathrm{e}^{5,25}$.

\section{Methods}

Adults and embryos. Adult echinoderms were collected intertidally or by Scuba from various sites around San Juan Island, WA, USA. Embryos, larvae and juveniles were reared in filtered sea water as described ${ }^{27}$. Planktotrophic larvae were fed Rhodomonas lens and Dunaliella tertiolecta.

Antibody probes. Monoclonal antibody 4D9 (ref. 28) was used to detect Engrailed protein in the brittle star Amphipholis squamata. To authenticate binding, a fragment of engrailed spanning the epitope ${ }^{28}$ was amplified from genomic DNA using primers 5'-CGCCCTCGCACAGCCTTCA-3' and 5'TGGTTGTAMARDCCCTGHGCCAT- $3^{\prime}$, cloned into pCRScript (Stratagene), and sequenced (Sequenase, Amersham). The resulting sequence (Genbank accession no. U80674) was used to predict the amino-acid sequence of the
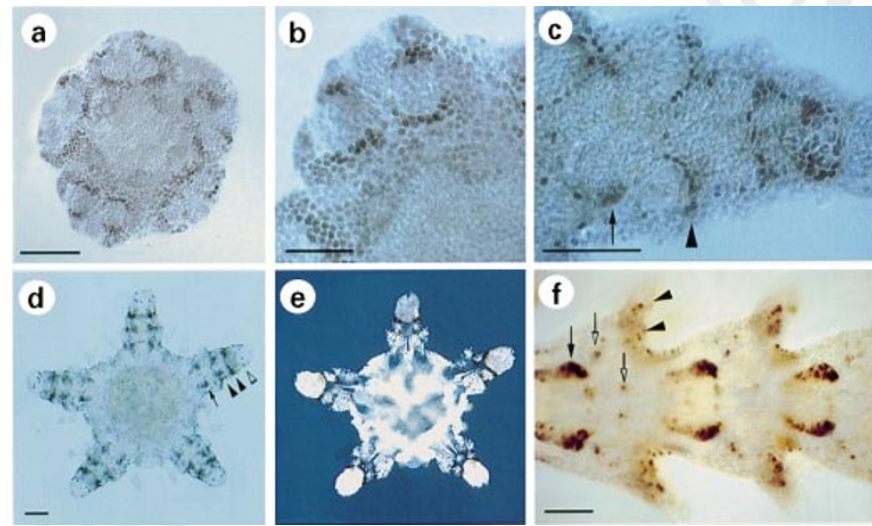

Figure 5 Expression of Engrailed protein in juvenile brittle stars (Amphipholis squamata). a, b. Pentagon stage, when skeletal ossicles are just beginning to form. Areas of active skeletogenesis, including the paired plates forming near future arms, are bounded by nuclei expressing engrailed protein. c. Arm tip of older juvenile, showing thin stripes of ectodermal expression (typically 1-2 cells wide; arrowhead) between forming ossicles. Stripes are transient, and fade within 3 arm segments proximally. Neuronal expression is out of the plane of focus (arrow). d, e, Juvenile under bright-field and polarizing light. Ectodermal stripes of expression are present between ossicles (filled arrowheads). A few nuclei have begun to express Engrailed protein where the boundary of the next arm segment will appear (open arrowhead). Neuronal expression is present in the older, more proximal arm segments (arrow). f, Decalcified arm of juvenile, showing neuronal expression primarily within repeated, paired ganglia (filled arrow), and in a few additional cells of unknown identity (open arrows). A few lateral cells within the ectoderm also express Engrailed protein, in areas between and adjacent to the lateral spine ossicles (arrowheads) as they form. Scale bars: a, d, e, $100 \mu \mathrm{m} ; \mathbf{b}$ $50 \mu \mathrm{m} ; \mathbf{c}, \mathbf{f}, 500 \mu \mathrm{m}$. epitope. Artificial peptides were synthesized (Bio-Synthesis) to this region of Engrailed protein from Drosophila melanogaster (positive $\operatorname{control}^{28}$ ), Helobdella triserialis (negative control ${ }^{23}$ ) and Amphipholis squamata (test case). Both the Drosophila and Amphipholis Engrailed fragments bound antibody on dot blots and competed with Amphipholis samples for antibody binding, whereas the Helobdella fragment did neither; both results suggest that the antibody 4D9 recognizes Engrailed protein in Amphipholis. Unfortunately, this antibody could not be used to examine engrailed expression in sea urchins, where an amino-acid substitution in the epitope interferes with binding ${ }^{28}$. A polyclonal antibody raised to a fusion protein containing Orthodenticle ${ }^{19}$ from the sea urchin Strongylocentrotus purpuratus was used to analyse orthodenticle expression in a variety of echinoderms. A polyclonal antibody raised to a fusion protein containing Distal-less from the butterfly Precis coenia and having very broad phylogenetic cross-reactivity ${ }^{9}$ was used to analyse distal-less expression in echinoderms.

Immunolocalization. Samples were fixed in $4 \%$ formaldehyde in phosphatebuffered saline for 10-30 min at room temperature, washed, dehydrated and stored in $75 \%$ ethanol at $-20^{\circ} \mathrm{C}$. Blanking, probing and detection (diaminobenzidine $/ \mathrm{Ni}^{2+}$ ) were performed as described ${ }^{29}$. Samples were mounted in phosphate-buffered saline or cleared using a mixture of benzylbenzoate and benzyl alcohol before photography.

Received 2 April; accepted 7 July 1997.

1. Hyman, L. The Invertebrates Vol. 4, Echinodermata (McGraw-Hill, New York, 1955).

2. Brusca, R. C. \& Brusca, G. J. Invertebrates (Sinauer, Sunderland, MA, 1990).

3. Jefferies, R. P. S., Brown, N. A. \& Daley, P. E. J. The early phylogeny of chordates and echinoderms and the origin of chordate left-right asymmetry and bilateral symmetry. Acta Zool. 77, 101-122 (1996).

4. Holland, N. D. in Echinoderm Phylogeny and Evolutionary Biology (eds Paul, C. R. C. \& Smith, A. B.) 13-25 (Clarendon, Oxford, 1988).

5. Raff, R. The Shape of Life (Chicago Univ. Press, 1996).

6. Nielsen, C. Animal Evolution: Interrelationships of the Animal Phyla (Oxford Univ. Press, 1995).

7. Turbeville, J. M., Schulz, J. R. \& Raff, R. A. Deuterostome phylogeny and the sister group of the chordates: evidence from molecules and morphology. Mol. Biol. Evol. 11, 648-655 (1994)

8. Duboule, D. (ed) Guidebook to the Homeobox Genes (Oxford Univ. Press, 1994).

9. Panganiban, G. et al. The origin and evolution of animal appendages. Proc. Natl Acad. Sci. USA 94, 5162-5166 (1997).

10. Patel, N. H. Developmental evolution: insights from studies of insect segmentation. Science 266, 581590 (1994).

11. Finkelstein, R. \& Boncinelli, E. From fly head to mammalian forebrain: the story of otx and Otd. Trends Genet. 10, 310-315 (1994).

12. Dickinson, J. Molecules and morphology: where's the homology? Trends Genet. 11, 119-121 (1995).

13. Bolker, J. \& Raff, R. A. Developmental genetics and traditional homology. BioEssays 18, 489-494 (1996).

14. David, B. \& Mooi, R. in Proceedings of the 9th International Echinoderm Conference (eds Mooi, R. \& Telford, M.) (Balkema, Amsterdam, in the press).

15. Malinda, K. M. \& Ettensohn, C. A. Primary mesenchyme cell migration in the sea urchin embryo: distribution of directional cues. Dev. Biol. 164, 562-578 (1994).

16. Kumé, M. \& Dan, K. Invertebrate Embryology (NOLIT, Belgrade, 1968).

17. Holland, P. W. H. Homeobox genes and segmentation: co-option, co-evolution, and convergence. Semin. Sev. Biol. 1, 135-145 (1990).

18. Averof, M., Dawes, R. \& Ferrier, D. Diversification of arthropod Hox genes as a paradigm for the evolution of gene functions. Semin. Cell Dev. Biol. 7, 539-551 (1996).

19. Gan, L. et al. An orthodentical-related protein from Strongylocentrotus purpuratus. Dev. Biol. 167, 517-528 (1995).

20. Dolecki, G. J. \& Humphreys, T. An engrailed class homeo box gene in sea urchins. Gene 64, 21-31 (1988).

21. Sharman, A. C. \& Holland, P. W. H. Conservation, duplication, and divergence of developmental genes during chordate evolution. Neth. J. Zool. 46, 47-67 (1996).

22. Smith, A. B. in Echinoderm Phylogeny and Evolutionary Biology (eds Paul, C. R. C. \& Smith, A. B.) 8597 (Clarendon, Oxford, 1988).

23. Wedeen, C. J. \& Weisblat, D. A. Segmental expression of an engrailed-class gene during early development and neurogenesis in an annelid. Development 113, 805-814 (1991).

24. Lacalli, T. C. Mesodermal pattern and pattern repeats in the starfish bipinnaria larva, and related patterns in other deuterostome larvae and chordates. Phil. Trans. R. Soc. Lond. B 351, 1737-1758 (1996).

25. Slack, J. M. W., Holland, P. W. H. \& Graham, C. F. The zootype and the phylotypic stage. Nature 361, 490-492 (1993).

26. DeRobertis, E. M. \& Sasai, Y. A common plan for dorsoventral patterning in Bilateria. Nature 380, $37-$ 40 (1996).

27. Strathmann, M. F. Reproduction and Development of Marine Invertebrates of the Northern Pacific Coast (Univ. Washington Press, Seattle, WA, 1987).

28. Patel, N. H. et al. Expression of engrailed proteins in arthropods, annelids, and chordates. Cell 58, 955-968 (1989).

29. Patel, N. H. Imaging neuronal subsets and other cell types in whole mount Drosophila embryos and larvae using antibody probes. Methods. Cell Biol. 44, 446-487.

Acknowledgements. We thank S. Carroll, W. Klein, G. Panganiban, N. Patel and A. Wikramanyake for sharing probes, primers and unpublished results; D. Brumbaugh, E. Inyengar, T. Gage, K. BrittonSimmons, D. Janies, L. Kuprianova, A. McNees, G. Miklos and B. Pernet for helping to collect animals; M. Thorndyke for help interpreting engrailed neuron expression; D. Willows, R. Strathmann and the staff of Friday Harbor Laboratories for providing facilities; and A. Bely, E. Knott, F. Hotchkiss, L. Issel-Tarver, T. Lacalli, L McEdward, R. Mooi, E. Popodi, R. Raff and J. Stone for discussions. This work was supported by grants to C.J.L. from the Sigma Xi Foundation and to G.A.W. from the NSF and A. P. Sloan Foundation.

Correspondence and requests for materials should be addressed to G.A.W. (e-mail: gwray@life.bio. sunysb.edu). 